\title{
PENENTUAN NILAI DEFLEKSI MAKSIMUM PADA JEMBATAN STEEL BOX GIRDER BERDASARKAN DATA NILAI ROTASI
}

\author{
David Surachmat $^{1}$, Made Suangga ${ }^{2}$ \\ ${ }^{1}$ Jurusan Teknik Sipil, Universitas Tarumanagara Jakarta \\ Email: davids.deca@gmail.com \\ ${ }^{2}$ Departemen Sipil, Universitas Universitas Tarumanagara Jakarta \\ Email: suangga@binus.edu
}

Masuk: 09-02-2021, revisi: 26-09-2021, diterima untuk diterbitkan: 06-10-2021

\begin{abstract}
ABSTRAK
Pemantauan kesehatan struktur jembatan (structural health monitoring system) sangat penting dilakukan untuk memastikan jembatan tetap dalam kondisi yang memadai. Banyak cara yang dapat dilakukan untuk memonitor kondisi jembatan, salah satunya dengan menggunakan Global Positioning System (GPS). Walaupun menghasilkan data yang akurat, penggunaan GPS dipandang menghabiskan biaya yang relatif besar. Adapun solusi yang lebih praktis dan murah untuk memprediksi defleksi yaitu dengan menggunakan tiltmeter dengan data rotasi. Pada studi ini, telah dipelajari tingkat akurasi defleksi jembatan steel box girder dengan bentang sederhana dari hasil persamaan regresi dengan data rotasi. Hasil analisis menunjukkan bahwa model regresi linear dan kuadratik 3D untuk 2 data rotasi memiliki tingkat akurasi lebih baik jika dibandingkan dengan model regresi linear dan kuadratik $2 \mathrm{D}$ untuk 2 data rotasi.
\end{abstract}

Kata Kunci: defleksi; rotasi; structural health monitoring system; tiltmeter

\begin{abstract}
Structural health monitoring system plays a crucial role in order to ensure a well-maintained bridge condition. There are a number of methods that may be utilized in order to conduct the monitoring process, namely the use of Global Positioning System (GPS). Despite its accuracy, the use of GPS is deemed costly. A more practical and economical approach to predicting deflection is the use of tiltmeter to obtain rotational values. This research studied the accuracy of simple span steel box girder deflection that is obtained from regression formulae. The analysis showed that a $3 D$ linear and quadratic regression with two rotation data provided the best accuracy if compared with $2 D$.
\end{abstract}

Keywords: deflection; rotation; structural health monitoring system; tiltmeter

\section{PENDAHULUAN}

Jembatan merupakan suatu konstruksi penghubung antarsungai, jalan dan rintangan fisik lainnya. Untuk memastikan bahwa jembatan selalu berada dalam kondisi baik diperlukan suatu upaya untuk memonitor kondisi struktur jembatan yang disebut sistem pemantauan kesehatan struktur atau structural health monitoring systems. Beberapa dekade terakhir dilakukan penerapan sistem yang berbasis komputer agar informasi kesehatan struktur diperoleh tepat waktu, berkelanjutan dan ekonomis (Brownjohn, 2006).

Secara umum, pemantauan kesehatan struktur bertujuan untuk mendeteksi kerusakan struktur, memprediksi umur layan struktur, dan menyediakan data agar proses pemeliharaan seoptimal mungkin dari segi biaya (Liu, 2009). 
Defleksi vertikal merupakan parameter yang sangat penting untuk dimonitor dengan tujuan untuk memastikan jembatan tetap dalam kondisi yang memadai. pengukuran defleksi jembatan seringkali tidak mudah bahkan tidak dimungkinkan karena kondisi fisik atau iklim. Upaya untuk mengukur defleksi pada jembatan telah dilakukan yaitu dengan menerapkan teknologi GPS (Ozakgul dkk, 2009). Penerapan GPS dirasa mahal, oleh sebab itu perlu adanya alternatif untuk menentukan defleksi pada jembatan. Penempatan tiltmeter ataupun strain gauge merupakan upaya pendekatan yang cepat untuk memonitor defleksi (Sousa dkk., 2013).

Zhang dkk. (2006) meneliti tentang estimasi defleksi jembatan melalui data inklinometer pada jembatan cable-stayed dengan mempertimbangkan kerusakan struktural. Hasil penelitian Zhang dkk. menunjukkan bahwa perkiraan defleksi sangat akurat dengan perbedaan $0 \%$.

Penuntun dkk. (2019) meneliti tentang defleksi pada jembatan Soekarno dengan jenis jembatan cable-stayed. Hasil penelitian Penuntun dkk. menunjukkan bahwa dengan menggunakan metode pendekatan Lagrange Interpolation Half dengan 24 tiltmeter memberikan hasil yang sangat baik dengan perbedaan defleksi maksimum hanya sebesar $1,056 \mathrm{~mm}$ dan dengan rata-rata perbedaan $0,722 \mathrm{~mm}$.

Tiltmeter merupakan solusi yang lebih praktis dan murah untuk memprediksi defleksi dengan menggunakan data rotasi. Dari permasalahan tersebut penting untuk mengetahui korelasi defleksi dari data rotasi (Haripriambodo, 2019).

\section{Tujuan penelitian}

Dalam studi ini akan dibahas persamaan korelasi defleksi dari data rotasi pada jembatan steel box girder bentang sederhana dengan mengusulkan metode baru yang lebih sederhana, praktis dan berbiaya rendah untuk mengukur defleksi jembatan dengan data rotasi. Selain itu memberikan informasi tingkat keakuratan analisis dua dimensi dibandingkan dengan tiga dimensi dalam memperkirakan defleksi berdasarkan rotasi.

\section{METODE PENELITIAN}

\section{Prosedur analisis}

Prosedur analisis dapat dijabarkan sebaga berikut:

a. Melakukan pemodelan struktur dan masukan variasi beban pada jembatan steel box girder bentang sederhana dengan panjang bentang $60 \mathrm{~m}$ untuk kasus 2D dan 3D menggunakan perangkat lunak FEM.

b. Melakukan analisis regresi linear dan kuadratik dengan perangkat lunak statistika berdasarkan data defleksi dan rotasi keluaran perangkat lunak FEM untuk mendapatkan persamaan regresi kasus 2D dan 3D.

c. Memeriksa tingkat akurasi defleksi maksimum dengan memasukan nilai rotasi pada persamaan terhadap hasil FEM untuk kasus 2D dan 3D.

d. Membandingkan tingkat akurasi persamaan 2D dan 3D.

\section{HASIL DAN PEMBAHASAN}

\section{Data jembatan}

Pada penelitian ini jembatan yang digunakan ialah steel box girder dengan panjang $60 \mathrm{~m}$ dan jenis bentang merupakan bentang sederhana. Potongan memanjang dan melintang pada jembatan yang akan diteliti dapat dilihat pada Gambar 1 dan 2, sedangkan spesifikasi teknis pada jembatan ini dapat dilihat pada Tabel 1. 


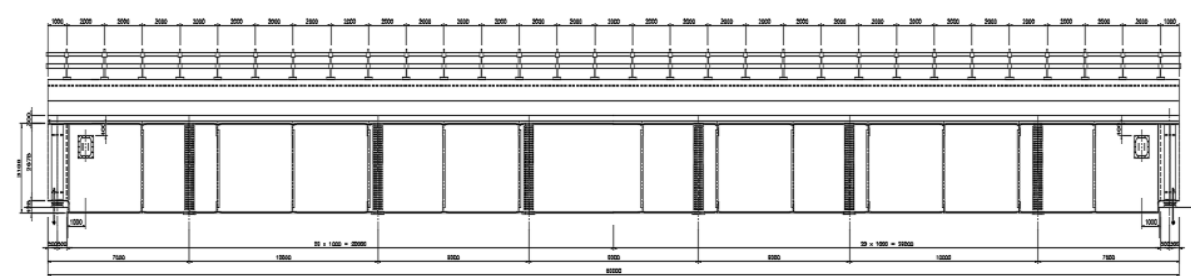

Gambar 1. Potongan memanjang jembatan

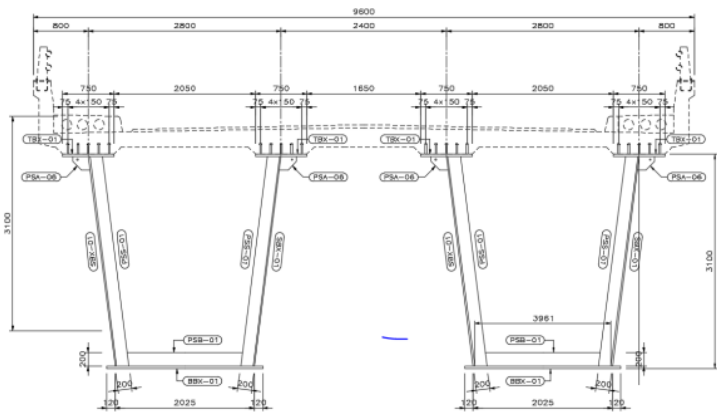

Gambar 2. Potongan melintang jembatan

Tabel 1. Spesifikasi teknis jembatan

\begin{tabular}{|c|c|}
\hline Modulus elastisitas $(\mathrm{MPa})$ & 200000 \\
\hline Jenis baja & SM 490 \\
\hline Kuat leleh minimum $(\mathrm{MPa})$ & 360 \\
\hline Kuat putus minimum $(\mathrm{MPa})$ & 490 \\
\hline Poisson Ratio & 0,3 \\
\hline
\end{tabular}

\section{Lokasi pengambilan data}

Tiap-tiap posisi pengukuran defleksi dan rotasi pada analisis 2 dimensi dan 3 dimensi memiliki jumlah data rotasi sebanyak 2 data rotasi dan defleksi sebanyak 1 data. Gambar 3 menunjukkan posisi pengukuran defleksi dan rotasi pada tesis ini.

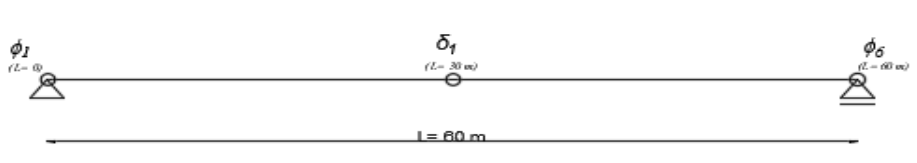

Gambar 3. Posisi pengukuran defleksi dan 2 data rotasi pada tumpuan kasus 2D dan 3D

\section{Analisis 2D dan 3D}

Analisis 2D

Pada analisis 2D jembatan dimodelkan dengan menggunakan 1 girder. Pemodelan struktur 2D pada perangkat lunak FEM dapat dilihat pada Gambar 4.

Gambar 4. Pemodelan struktur 2D 
Terdapat 20 posisi beban pada analisis 2D yang dimasukan. Posisi beban 2D dapat dilihat pada Tabel 2.

Tabel 2. Posisi beban 2D

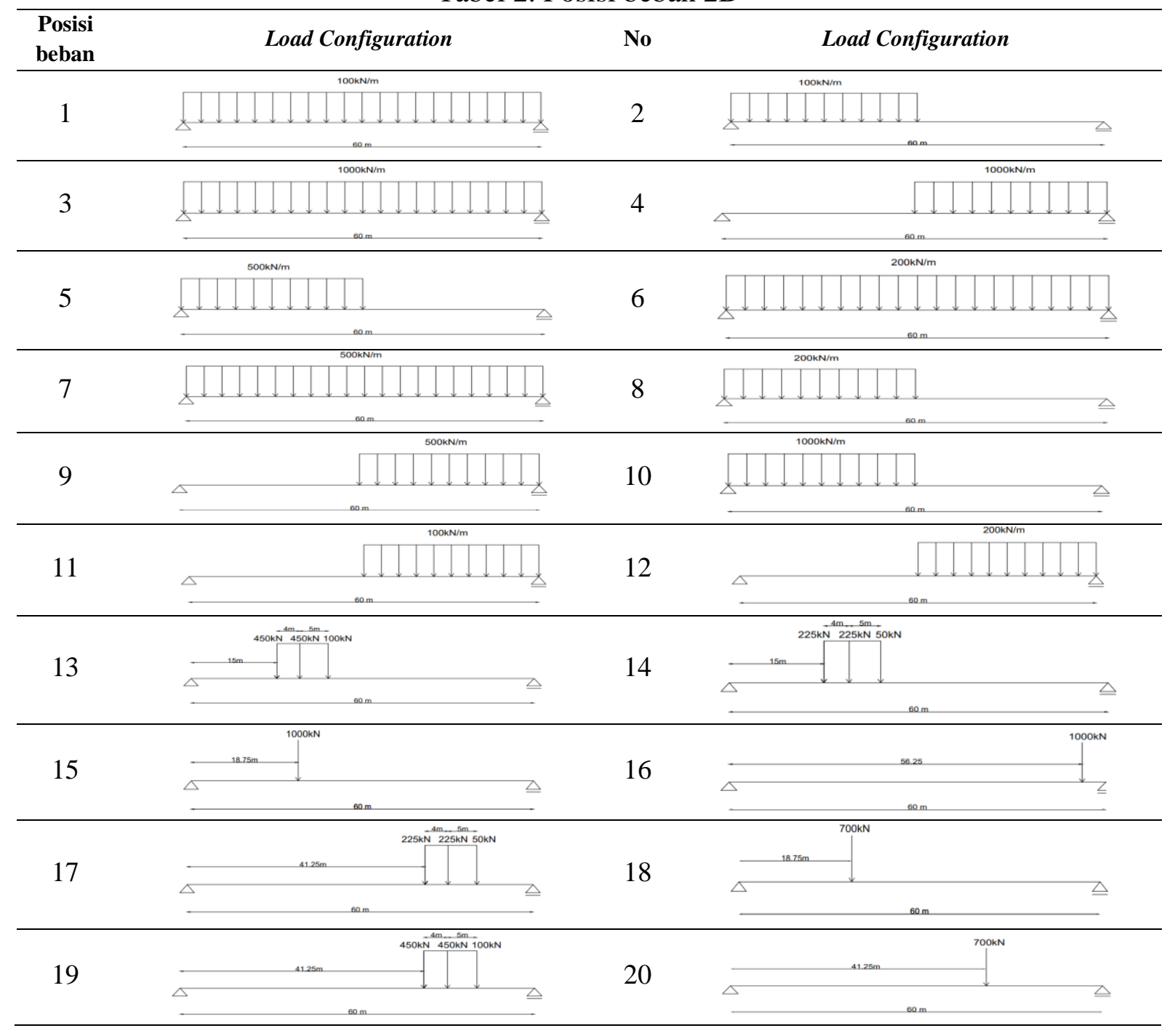

Hasil analisis dua dimensi berupa data nilai defleksi dan data rotasi yang kemudian diolah dengan menggunakan perangkat lunak statistika sehingga didapatkan persamaan regresi. Hasil FEM dan persamaan regresi dapat dilihat pada Tabel 3 dan Tabel 4. 
Tabel 3. Hasil FEM 2D

\begin{tabular}{|c|c|c|c|}
\hline Posisi & $\delta(\mathbf{m m})$ & $\Phi_{1}(\operatorname{Rad})$ & $\Phi_{2}(\operatorname{Rad})$ \\
\hline Beban & $(\mathbf{L}=\mathbf{3 0 m})$ & $(\mathbf{L}=\mathbf{0 m})$ & $(\mathrm{L}=60 \mathrm{~m})$ \\
\hline PB1 & -124.2 & 0.00641 & -0.00641 \\
\hline PB2 & -62.1 & 0.00361 & -0.0028 \\
\hline PB3 & -1242.4 & 0.06411 & -0.06411 \\
\hline PB4 & -621.2 & 0.02805 & -0.03606 \\
\hline PB5 & -310.6 & 0.01803 & -0.01402 \\
\hline PB6 & -248.5 & 0.01282 & -0.01282 \\
\hline PB7 & -621.2 & 0.03206 & -0.03206 \\
\hline PB8 & -124.2 & 0.00721 & -0.00561 \\
\hline PB9 & -310.6 & 0.01402 & -0.01803 \\
\hline PB10 & -621.2 & 0.03606 & -0.02805 \\
\hline PB11 & -62.1 & 0.0028 & -0.00361 \\
\hline PB12 & -124.2 & 0.0056 & -0.00721 \\
\hline PB13 & -25.6075 & 0.0015 & -0.00114 \\
\hline PB14 & -12.8037 & 0.00075 & -0.00057 \\
\hline PB15 & -26.9788 & 0.00155 & -0.00121 \\
\hline PB16 & -26.9788 & 0.00121 & -0.00155 \\
\hline PB17 & -11.5211 & 0.00051 & -0.0007 \\
\hline PB18 & -18.8852 & 0.00108 & -0.00084 \\
\hline PB19 & -23.0422 & 0.00102 & -0.0014 \\
\hline PB20 & -18.8852 & 0.00084 & -0.00108 \\
\hline
\end{tabular}

Keterangan:

$\boldsymbol{\delta}=$ Lendutan

$\Phi \quad=$ Putaran sudut

Tabel 4. Persamaan regresi linear dan kuadratik dua dimensi

\begin{tabular}{cc}
\hline Jumlah Data Rotasi & Persamaan Regresi Linear \\
\hline $2(L=0$ dan $L=60 m)$ & $\delta=0,042-9689,276 \phi_{1}+9688,667 \phi_{2}$ \\
\hline Jumlah Data Rotasi & Persamaan Regresi Kuadratik \\
\hline $2(L=0$ dan $L=60 \mathrm{~m})$ & $\delta=-0,054-9693,393 \phi_{1}+9680,985 \phi_{2}-1525,59 \phi_{1} \phi_{2}-686,299 \phi_{1}{ }^{2}-$ \\
$898,121 \phi_{2}{ }^{2}$
\end{tabular}

Perbedaan defleksi hasil FEM dibandingkan dengan defleksi hasil regresi untuk kasus 2D dapat dilihat pada Tabel 5. 
Tabel 5. Defleksi FEM vs defleksi regresi 2D

\begin{tabular}{cccccccc}
\hline & & \multicolumn{3}{c}{ Linear } & & \multicolumn{3}{c}{ Kuadratik } \\
\cline { 3 - 8 } $\begin{array}{c}\text { Posisi } \\
\text { Beban }\end{array}$ & $\begin{array}{c}\boldsymbol{\delta} \text { FEM } \\
(\mathbf{m m})\end{array}$ & $\begin{array}{c}\boldsymbol{\delta} \\
\text { Regresi } \\
(\mathbf{m m})\end{array}$ & $\begin{array}{c}\text { Perbedaan } \\
\text { Lendutan } \\
(\mathbf{m m})\end{array}$ & $\begin{array}{c}\text { Persentase } \\
\text { Perbedaan } \\
(\boldsymbol{\%})\end{array}$ & $\begin{array}{c}\boldsymbol{\delta} \\
\text { Regresi } \\
(\mathbf{m m})\end{array}$ & $\begin{array}{c}\text { Perbedaan } \\
\text { Lendutan } \\
(\mathbf{m m})\end{array}$ & $\begin{array}{c}\text { Persentase } \\
\text { Perbedaan } \\
(\boldsymbol{\%})\end{array}$ \\
\hline PB1 & -124.2 & -124.254 & 0.054408 & 0.043807 & -124.247 & 0.046509 & 0.037447 \\
\hline PB2 & -62.1 & -62.1483 & 0.048348 & 0.077855 & -62.1548 & 0.054798 & 0.088242 \\
\hline PB3 & -1242.4 & -1242.36 & 0.038281 & 0.003081 & -1242.39 & 0.012463 & 0.001003 \\
\hline PB4 & -621.2 & -621.199 & 0.000685 & 0.00011 & -621.215 & 0.015059 & 0.002424 \\
\hline PB5 & -310.6 & -310.575 & 0.025448 & 0.008193 & -310.568 & 0.032382 & 0.010425 \\
\hline PB6 & -248.5 & -248.467 & 0.032977 & 0.013271 & -248.444 & 0.056473 & 0.022725 \\
\hline PB7 & -621.2 & -621.299 & 0.098646 & 0.01588 & -621.257 & 0.057372 & 0.009236 \\
\hline PB8 & -124.2 & -124.255 & 0.054896 & 0.0442 & -124.256 & 0.056253 & 0.045292 \\
\hline PB9 & -310.6 & -310.572 & 0.027892 & 0.00898 & -310.545 & 0.054915 & 0.01768 \\
\hline PB10 & -621.2 & -621.204 & 0.004198 & 0.000676 & -621.206 & 0.005672 & 0.000913 \\
\hline PB11 & -62.1 & -62.1479 & 0.047854 & 0.077059 & -62.1458 & 0.045847 & 0.073828 \\
\hline PB12 & -124.2 & -124.157 & 0.042972 & 0.034599 & -124.144 & 0.056156 & 0.045214 \\
\hline PB13 & -25.6075 & -25.6208 & 0.013288 & 0.051891 & -25.6308 & 0.023341 & 0.091148 \\
\hline PB14 & -12.8037 & -12.8313 & 0.027591 & 0.215491 & -12.8426 & 0.038857 & 0.303483 \\
\hline PB15 & -26.9788 & -26.7835 & 0.195341 & 0.724055 & -26.7932 & 0.185621 & 0.688025 \\
\hline PB16 & -26.9788 & -26.7833 & 0.195549 & 0.724824 & -26.7892 & 0.189641 & 0.702925 \\
\hline PB17 & -11.5211 & -11.7654 & 0.244291 & 2.12038 & -11.7747 & 0.253619 & 2.201344 \\
\hline PB18 & -18.8852 & -18.6447 & 0.240508 & 1.273526 & -18.6553 & 0.229933 & 1.217528 \\
\hline PB19 & -23.0422 & -23.489 & 0.446789 & 1.939002 & -23.4953 & 0.453061 & 1.966223 \\
\hline PB20 & -18.8852 & -18.6445 & 0.240654 & 1.274301 & -18.6524 & 0.232813 & 1.23278 \\
\hline & Rata-Rata & & $\mathbf{0 . 1 0 4 0 3 1}$ & $\mathbf{0 . 4 3 2 5 5 9}$ & & $\mathbf{0 . 1 0 5 0 3 9}$ & $\mathbf{0 . 4 3 7 8 9 4}$ \\
\hline & & & & & & & \\
\hline
\end{tabular}

Analisis 3D

Pada analisis 3D semua komponen jembatan dimodelkan. Pemodelan struktur 3D pada perangkat lunak FEM dapat dilihat pada Gambar 5.

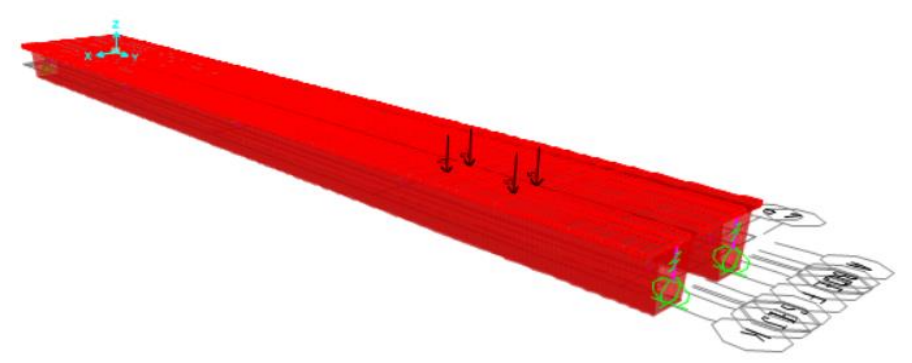

Gambar 5. Pemodelan Struktur 3D 
Terdapat 20 posisi beban pada analisis 3D yang dimasukan. Posisi beban pada pemodelan struktur 3D dapat dilihat pada Tabel 6.

Tabel 6. Posisi beban 3D

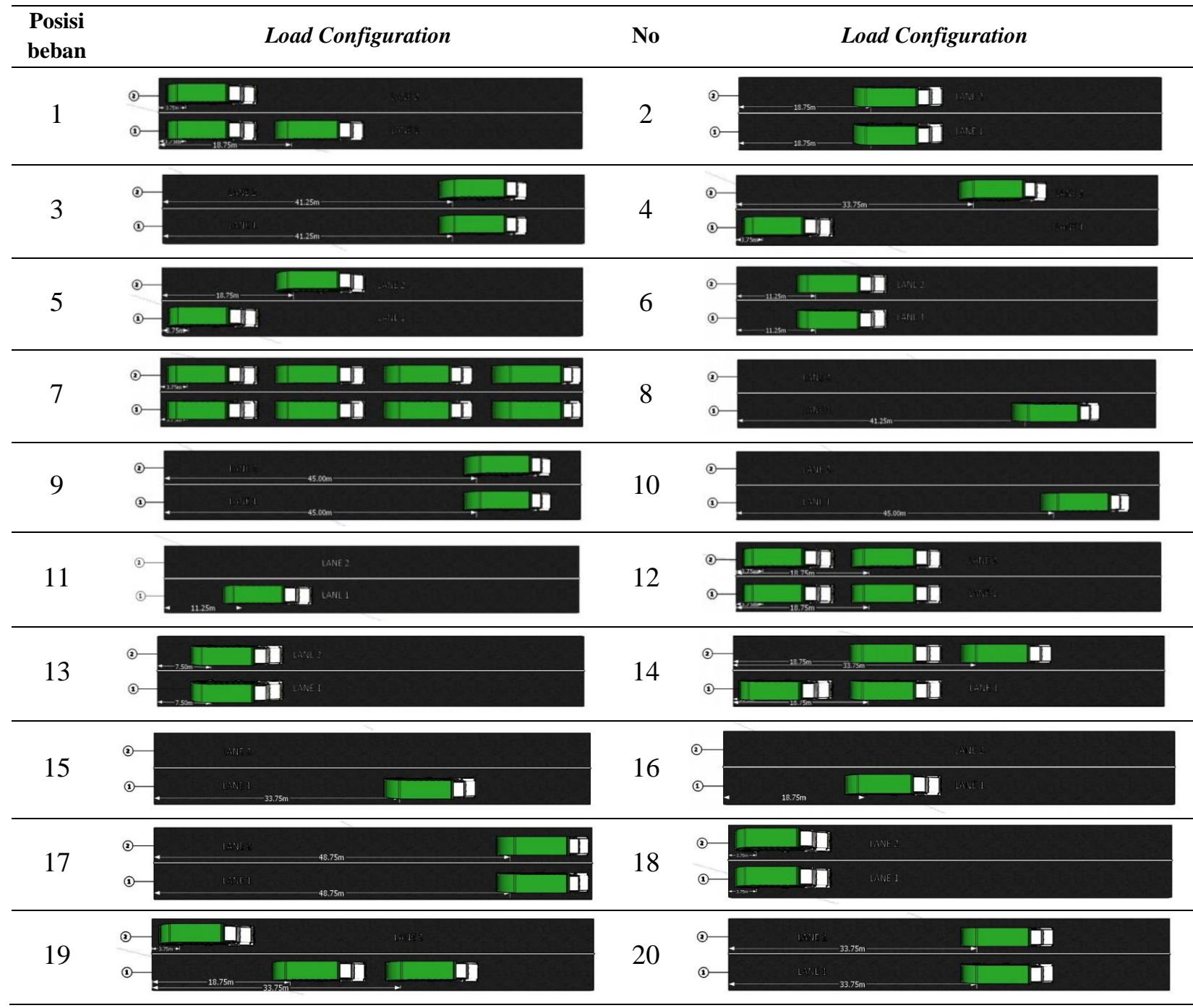

Hasil analisis dua dimensi berupa data nilai defleksi dan data rotasi yang kemudian diolah dengan menggunakan perangkat lunak statistika sehingga didapatkan persamaan regresi. Hasil FEM dan persamaan regresi dapat dilihat pada Tabel 7 dan Tabel 8. 
Tabel 7. Hasil FEM 3D

\begin{tabular}{|c|c|c|c|}
\hline Posisi & $\delta(\mathbf{m m})$ & $\Phi_{1}(\operatorname{Rad})$ & $\Phi_{2}(\operatorname{Rad})$ \\
\hline Beban & $(\mathrm{L}=\mathbf{3 0 m})$ & $(\mathbf{L}=\mathbf{0 m})$ & $(\mathrm{L}=60 \mathrm{~m})$ \\
\hline 1 & -10.0518 & 0.00083 & -0.00051 \\
\hline 2 & -10.5776 & 0.0008 & -0.00061 \\
\hline 3 & -9.0791 & 0.00048 & -0.00073 \\
\hline 4 & -7.6531 & 0.00054 & -0.00048 \\
\hline 5 & -7.4278 & 0.0006 & -0.00039 \\
\hline 6 & -8.178 & 0.00068 & -0.00041 \\
\hline 7 & -31.6366 & 0.00211 & -0.00211 \\
\hline 8 & -4.9545 & 0.00026 & -0.0004 \\
\hline 9 & -7.5731 & 0.00037 & -0.00064 \\
\hline 10 & -4.1994 & 0.0002 & -0.00036 \\
\hline 11 & -4.5036 & 0.00038 & -0.00022 \\
\hline 12 & -14.9171 & 0.00119 & -0.0008 \\
\hline 13 & -6.4468 & 0.00056 & -0.0003 \\
\hline 14 & -18.2145 & 0.00134 & -0.00109 \\
\hline 15 & -5.9213 & 0.00036 & -0.00043 \\
\hline 16 & -5.696 & 0.00043 & -0.00033 \\
\hline 17 & -5.7076 & 0.00026 & -0.0005 \\
\hline 18 & -4.3557 & 0.00039 & -0.00019 \\
\hline 19 & -13.4106 & 0.00095 & -0.00084 \\
\hline 20 & -11.0119 & 0.00066 & -0.00081 \\
\hline
\end{tabular}

Keterangan:

$\boldsymbol{\delta} \quad=$ Lendutan

$\Phi \quad=$ Putaran sudut

Tabel 8. Persamaan regresi linear dan kuadratik tiga dimensi

\begin{tabular}{cc}
\hline Jumlah Data Rotasi & Persamaan Regresi Linear \\
\hline $2(\mathrm{~L}=0$ dan $\mathrm{L}=60 \mathrm{~m})$ & $\delta=-0,005-7494,924 \phi_{1}+7494,073 \phi_{2}$ \\
\hline Jumlah Data Rotasi & Persamaan Regresi Kuadratik \\
\hline $2(\mathrm{~L}=0$ dan $\mathrm{L}=60 \mathrm{~m})$ & $\delta=-0,010-7489,546 \phi_{1}+7478,639 \phi_{2}-116522,203 \phi_{1} \phi_{2}-58373 \phi_{1}{ }^{2}+$ \\
& $-67762,452 \phi_{2}{ }^{2}$ \\
\hline
\end{tabular}

Perbedaan defleksi hasil FEM dibandingkan dengan defleksi hasil regresi untuk kasus 2D dapat dilihat pada Tabel 9. 
Tabel 9. Defleksi FEM vs defleksi regresi 2D

\begin{tabular}{|c|c|c|c|c|c|c|c|}
\hline \multirow[b]{2}{*}{$\begin{array}{l}\text { Posisi } \\
\text { Beban }\end{array}$} & \multirow[b]{2}{*}{$\begin{array}{c}\text { ס FEM } \\
(\mathbf{m m})\end{array}$} & \multicolumn{3}{|c|}{ Linear } & \multicolumn{3}{|c|}{ Kuadratik } \\
\hline & & $\begin{array}{c}\delta \\
\text { Regresi } \\
(\mathrm{mm})\end{array}$ & $\begin{array}{c}\text { Perbedaan } \\
\text { Lendutan } \\
(\mathbf{m m})\end{array}$ & $\begin{array}{c}\text { Persentase } \\
\text { Perbedaan } \\
(\%)\end{array}$ & $\begin{array}{c}\delta \\
\text { Regresi } \\
(\mathbf{m m})\end{array}$ & $\begin{array}{c}\text { Perbedaan } \\
\text { Lendutan } \\
(\mathbf{m m})\end{array}$ & $\begin{array}{c}\text { Persentase } \\
\text { Perbedaan } \\
\quad(\%)\end{array}$ \\
\hline 1 & -10.0518 & -10.0481 & 0.0037318 & 0.037126 & -10.0494 & 0.00237294 & 0.023607 \\
\hline 2 & -10.5776 & -10.5726 & 0.0049722 & 0.0470073 & -10.5698 & 0.00779947 & 0.073736 \\
\hline 3 & -9.0791 & -9.07354 & 0.0055591 & 0.06123 & -9.0736 & 0.00549757 & 0.060552 \\
\hline 4 & -7.6531 & -7.64972 & 0.003382 & 0.0441908 & -7.64702 & 0.00608342 & 0.07949 \\
\hline 5 & -7.4278 & -7.42495 & 0.0028531 & 0.0384112 & -7.42494 & 0.00286487 & 0.03857 \\
\hline 6 & -8.178 & -8.17442 & 0.0035777 & 0.0437483 & -8.17551 & 0.00248698 & 0.030411 \\
\hline 7 & -31.6366 & -31.6321 & 0.0045122 & 0.0142627 & -31.6362 & 0.00044629 & 0.001411 \\
\hline 8 & -4.9545 & -4.95161 & 0.0028865 & 0.0582606 & -4.95189 & 0.00260932 & 0.052666 \\
\hline 9 & -7.5731 & -7.57463 & 0.0015327 & 0.0202381 & -7.5761 & 0.00299875 & 0.039597 \\
\hline 10 & -4.1994 & -4.20216 & 0.0027551 & 0.0656075 & -4.20343 & 0.00402997 & 0.095965 \\
\hline 11 & -4.5036 & -4.50207 & 0.0015288 & 0.0339462 & -4.50378 & 0.00017904 & 0.003975 \\
\hline 12 & -14.9171 & -14.9195 & 0.002422 & 0.0162363 & -14.9211 & 0.0039556 & 0.026517 \\
\hline 13 & -6.4468 & -6.45068 & 0.0038834 & 0.0602369 & -6.45305 & 0.00624967 & 0.096942 \\
\hline 14 & -18.2145 & -18.217 & 0.0025418 & 0.0139546 & -18.2133 & 0.00117717 & 0.006463 \\
\hline 15 & -5.9213 & -5.92593 & 0.0046281 & 0.0781596 & -5.92459 & 0.00329157 & 0.055589 \\
\hline 16 & -5.696 & -5.70117 & 0.0051654 & 0.0906853 & -5.70058 & 0.00457714 & 0.080357 \\
\hline 17 & -5.7076 & -5.70102 & 0.0065792 & 0.1152711 & -5.70282 & 0.00477638 & 0.083685 \\
\hline 18 & -4.3557 & -4.3522 & 0.0035018 & 0.0803948 & -4.35504 & 0.00066171 & 0.015192 \\
\hline 19 & -13.4106 & -13.4205 & 0.0099032 & 0.0738458 & -13.4151 & 0.00451928 & 0.033699 \\
\hline \multirow[t]{2}{*}{20} & -11.0119 & -11.0222 & 0.010253 & 0.0931086 & -11.0189 & 0.006975 & 0.063341 \\
\hline & Rata-Rata & & 0.0043085 & 0.0542961 & & 0.00367761 & 0.048088 \\
\hline
\end{tabular}

\section{Perbandingan tingkat akurasi $2 D$ VS $3 D$}

Dari persamaan regresi linear dan kuadratik untuk kasus 2D dan 3D dapat diperiksa tingkat akurasi persamaan regresi defleksi 2D dan persamaan regresi 3D dengan cara memasukan kembali data rotasi hasil FEM ke dalam tiap-tiap persamaan regresi yang telah dibuat sehingga dapat dibandingkan tingkat akurasi 2D dengan 3D. Hasil perbandingan tersebut dapat dilihat pada Tabel 10.

Tabel 10. Perbandingan tingkat akurasi persamaan $2 \mathrm{D}$ vs $3 \mathrm{D}$

\begin{tabular}{cccc}
\hline \multirow{2}{*}{$\begin{array}{c}\text { Jumlah Titik Rotasi } \\
\text { yang Diperhitungkan }\end{array}$} & $\begin{array}{c}\text { Derajat } \\
\text { Fungsi }\end{array}$ & \multicolumn{2}{c}{ Rata-Rata Perbedaan 2D vs 3D } \\
\cline { 3 - 4 } & Pendekatan & 2D & 3D \\
\hline \multirow{2}{*}{$2(\mathrm{~L}=0$ dan $\mathrm{L}=60 \mathrm{~m})$} & Linear & $0,1 \mathrm{~mm}(0,43 \%)$ & $0,0043 \mathrm{~mm}(0,054 \%)$ \\
\cline { 2 - 4 } & Kuadratik & $0,1 \mathrm{~mm}(0,43 \%)$ & $0,0036 \mathrm{~mm}(0,048 \%)$ \\
\hline
\end{tabular}




\section{KESIMPULAN DAN SARAN}

Dari hasil penelitian ini dapat ditarik beberapa kesimpulan sebagai berikut:

a. Hasil analisis pendekatan antara regresi linear dan kuadratik dengan menggunakan 2 data rotasi kasus 2D dan 3D mempunyai hasil yang hampir sama sebaiknya untuk keperluan praktis cukup digunakan regresi linear saja.

b. Analisis 2D jika dibandingkan dengan analisis 3D mempunyai hasil yang lebih akurat 3D dengan perbedaan $0,376 \%$ untuk regresis linear dan $0,382 \%$ untuk regresi kuadratik.

Adapun saran yang dapat diberikan untuk melengkapi studi ini dan untuk penelitian selanjutnya adalah sebagai berikut:
a. Perlu dilakukan lebih banyak variasi jenis beban dan jumlah beban.
b. Perlu dilakukan analisis dengan jenis bentang continuous span.
c. Menggunakan data regangan (strain gauge) untuk memprediksi lendutan.
d. Menggunakan jenis jembatan yang lain seperti salah satunya cable-stayed

\section{REFERENSI}

Brownjohn. (2006). Structural Health Monitoring of Civil Structures. Philosophical Transactions Royal Society A.

Harpriambodo, T. (2019). Numerical analysis of three span continuous bridge deflection by using rotation. International Journal of Innovative Research in Science. Engineering and Technology, 9-12.

Liu dkk,. (2009). Bridge System Performance Assessment from Structural Health Monitoring: A Case Study. ASCE, 1-2.

Ozakgul dkk,. (2009). Load Testing of Bridges Using Tiltmeters. Society for Experimental Mechanics Inc, 1.

Penuntun dkk,. (2019). Bridge Displacement Estimation using Tiltmeter Data. Journal of The Civil Engineering Forum, 105-111.

Sousa dkk,. (2013). Bridge Deflection Evaluation using Strain and Rotation Measurements, Article in Smart Structures and Systems, 5. 